\title{
UNUS MUNDUS E VISÃO DE MUNDO NA PSICOLOGIA ANALIITICA
}

\author{
UNUS MUNDUS AND WORLD VIEW IN ANALYTICAL PSYCHOLOGY \\ UNUS MUNDUS Y VISIÓN DE MUNDO EN LA PSICOLOGÍA ANALÍTICA
}

Luis Gustavo Vechi*

\begin{abstract}
RESUMO
Este artigo caracteriza a visão de mundo da Psicologia junguiana com base no conceito de unus mundus. A amostra com textos de Jung, de comentadores dele e de autores da Física Quântica foi analisada mediante a hermenêutica junguiana. Os resultados foram organizados por meio das seguintes categorias de análise: "o plano invisível subjacente ao nível empírico da realidade como totalidade e unidade", "o plano invisível como fonte de criação e de movimento", "o plano invisível como marcado pela não localidade" e "a psique e o plano invisível". A conclusão apontou para uma visão de mundo em que a realidade empírica é fundamentada em uma ordem implicada/invisível a qual é considerada fonte de criação, de movimento, de unidade, de conexão não causal e não condicionada pelo tempo e espaço. O arquétipo é considerado "ponte" entre a psique e essa ordem invisível, e a sincronicidade, evidência dessa conexão.
\end{abstract}

Palavras-chave: Psicologia analítica. Visão de mundo. Arquétipo. Sincronicidade.

\begin{abstract}
This article characterizes the world view of Jungian psychology based on the concept of unus mundus. A sample with articles by Jung, his commentators and authors of Quantum Physics was analyzed using Jungian hermeneutics. The results were organized according to the following analysis categories: "the invisible plane underlying the empirical level of reality as totality and unity", "the invisible plane as the source of creation and movement", "the invisible plane as marked by non-locality" and "the psyche and the invisible plane." The main conclusion that can be drawn is one of a worldview in which the empirical reality is seen as grounded in an implied/invisible order which is considered to be a source of creation, movement, unity, non-causal connection and unconditioned by time and space. Archetype is considered
\end{abstract}

Texto recebido em 30 de junho de 2017 e aprovado para publicação em 3 de maio de 2018.

"Doutor em Psicologia pelo Instituto de Psicologia da USP, membro do New Zealand College of Clinical Psychologists, psicólogo clínico e pesquisador no Waikato Hospital e em consultório particular, em Hamilton, Nova Zelândia, e pesquisador-colaborador do LEP - Laboratório de Estudos da Personalidade, Instituto de Psicologia da USP. Endereço: 5 Kennedy Lane, Hamilton East, 3216, Hamilton, New Zealand. Site: http://drluisgustavovechi.co.nz/.E-mail: lgvechi@gmail.com. 
a "bridge" between the psyche and the invisible order, and synchronicity as evidence of this connection.

Keywords: Analytical psychology. World view. Archetype. Synchronicity.

\section{RESUMEN}

Este artículo caracteriza la visión de mundo de la Psicología junguiana con base en el concepto de unus mundus. La muestra con textos de Jung, sus comentaristas y de autores de la Física Cuántica fue analizada por la hermenéutica junguiana. Los resultados se organizaron a través de las siguientes categorías de análisis: "el plano invisible subyacente al nivel empírico de la realidad como totalidad y unidad", "el plano invisible como fuente de creación y de movimiento", "el plano invisible como marcado por la no-localidad" y "la psique y el plano invisible". La conclusión señaló hacia una visión de mundo en que la realidad empírica está fundamentada en un orden implicado / invisible que se considera una fuente de creación, movimiento, unidad, conexión no causal y no condicionada por el tiempo y el espacio. Se considera el arquetipo un "puente" entre la psique y ese orden invisible, y la sincronicidad es la evidencia de esa conexión.

Palabras clave: Psicología analítica. Visión de mundo. Arquetipo. Sincronicidad.

\section{INTRODUÇÃO}

$\mathrm{N}$

Psicologia junguiana, a expressão visão de mundo foi introduzida pelo termo Weltanschauung. É muito difícil traduzir essa palavra alemã em outra língua, pois é dotada de um caráter psicológico específico, ou seja, ela expressa não somente uma concepção do mundo, mas também o modo como ele é considerado (Jung, 1991d).

A visão do mundo, entendida como a concepção que se tem da realidade e de seu funcionamento, tornou-se alvo de nosso interesse científico, porque, segundo Jung (1991b), as coisas são muito menos como elas são do que como nós a vemos. Nesse sentido,

Não é indiferente saber que espécie de cosmovisão possuímos, porque não formamos apenas uma imagem do mundo; esta imagem modifica-nos também retroativamente. O conceito que formamos a respeito do mundo é a imagem daquilo que chamamos mundo. E é por esta imagem que orientamos a adaptação de nós mesmos à realidade (Jung, 1991d, p. 308, \$\$ 696-697).

Pautado pela definição junguiana, Boyd (1991, p. 15) ratificou a importância de se esclarecer e investigar a visão do mundo contida nas diferentes teorias 
científicas e, assim, ajudou-nos a encontrar razão para propormos, a seguir, os objetivos deste artigo, ao indicar que "os diferentes modos de se explicar [. . .] um fenômeno são uma função da Weltanschauung do observador” (Boyd, 1991, p. 15). Esclarecer as diferentes visões de mundo contidas nas distintas teorias em Psicologia oferece a possibilidade de aprofundar o entendimento do recorte teórico que cada uma delas propõe e (re)cria ao ser utilizada.

Posto isso, propomos para este trabalho o objetivo de caracterizar aspectos da visão de mundo da Psicologia Analítica associados ao conceito de unus mundus empregado nessa vertente teórica. Como a Psicologia Analítica é extensa e multifacetada, escolhemos o conceito de unus mundus para a pesquisa acerca da visão de mundo junguiana, porque este conceito revela, em grande medida, aspectos importantes da perspectiva de realidade contida na teoria de Jung, conforme sugere Card (1991), Von Franz (1974; 2001) e Zinkin (1998). Para esses autores, o conceito de unus mundus oferece elementos relevantes da concepção de realidade e de sua relação com a psique, constituindo, assim, a nosso ver, campo fértil para pesquisa da visão de mundo da Psicologia Analítica. Apesar de não esgotar as possibilidades de caracterizar essa visão, este estudo, no limite da parcialidade, pretende esclarecer aspectos essenciais dela sob o prisma do conceito supramencionado.

Para desenvolvermos este artigo, o dividimos nas seguintes partes: método por meio do qual os procedimentos para responder ao objetivo deste estudo são apresentados, resultados do estudo e reflexões finais.

\section{MÉTODO}

\subsection{A amostra}

Para escolhermos os textos considerados como material empírico desta pesquisa, utilizamo-nos de quatro procedimentos principais: o primeiro procedimento correspondeu à consulta ao verbete unus mundus no General index to the collected works of C. G. Jung, de Forryan \& Glover (1979), para identificarmos os textos nos quais essa noção foi abordada.

O segundo procedimento foi o de ler esses textos e identificar outros conceitos importantes a serem pesquisados, também associados à visão de realidade na Psicologia Analítica. Desse modo, o General index foi consultado novamente para acessarmos escritos que desenvolvessem os seguintes conceitos: Weltanschauung, world-soul, psyche, alchemy, archetype psychoid, synchronicity, space-timeless e eternity. 
O terceiro procedimento foi o de consultar escritos de comentadores da obra de Jung que discorrem sobre os conceitos mencionados acima bem como a perspectiva de realidade associada a ele, como Card (1991), Cochrane, Flower, Mackenna e Morgan (2014), Pereira (1991; 1998), Stevens (2015), Vechi (2021 no prelo), Von Franz (1974; 2001) e Zinkin (1998). Esses autores se enquadram na vertente denominada "clássica" de pensamento dessa escola em Psicologia. Essa corrente mantém os principais conceitos de Jung e se encontra representada fundamentalmente pela produção ligada ao Instituto C. G. Jung de Zurich (Hard, 2008; Samuels, 2017).

No quarto procedimento, fizemos uma segunda leitura dos textos previamente identificados para selecionarmos apenas aqueles que abordavam diretamente a temática de interesse. Foram, assim, excluídos os textos nos quais o conceito de unus mundus não ganhou suficiente destaque para serem considerados neste trabalho.

\subsection{O procedimento de análise}

A amostra deste artigo foi analisada mediante a hermenêutica junguiana, tal como articulada por Vechi (2018), que propôs considerar o material empírico de uma pesquisa como símbolo, ou seja, como material com potencial de revelar novos e inéditos sentidos apreendidos na e pela relação estabelecida com o pesquisador, mediante quatro etapas distintas de leitura.

As três primeiras etapas foram definidas por Humbert (1985), por meio dos seguintes verbos no alemão: Geschehenlassen, Betrachten e Sich auseinandersetzen. Em português, Geschehenlassen significa "deixar acontecer", Betrachten, "engravidar e objetivar", e Sich auseinandersetzen, "confrontar-se com e se diferenciar de". Nesse sentido, a primeira etapa foi a de encontrar, com receptividade e aceitação, as primeiras impressões suscitadas pelos textos. Já a segunda permitiu que essas impressōes "penetrassem" em nosso campo do pensamento, do sentimento e das sensações, a fim de que "engravidássemos" e, assim, partindo das impressões, pudéssemos acessar sentidos nos textos lidos.

As quatro funções psíquicas propostas por Jung (1977) sensação, pensamento, sentimento e intuição foram considerados os canais principais para que o "processo de engravidamento" ocorresse. A sensação se refere à captação de informação mediante os cinco sentidos enquanto o pensamento traz definição e conceito ao que é percebido. O sentimento é uma função que define o valor do que é percebido, por exemplo, se isso é algo positivo ou negativo e a função intuitiva é uma percepção que não depende dos cinco sentidos, pois é uma 
captação via inconsciente. Nesse sentido, o "engravidamento" ocorreu a partir do pensamento, sensação, sentimento e intuição.

$\mathrm{Na}$ terceira etapa de leitura do material, confrontamos o que surgiu desse processo de diálogo com o material e organizamos os principais sentidos obtidos com a leitura. Nessa etapa, consideramos as nossas reações com o "engravidamento", mas sem perder de vista as características dos símbolos, ou seja, dos textos estudados. Como propôs Cochrane et al. (2014), tomamos o cuidado para, nessa etapa, não ficarmos presos às nossas reações e "mutilarmos" o material estudado. Buscamos, assim, considerar o efeito que os símbolos estudados nos gerou, ao mesmo tempo em que pretendemos preservar a "identidade", ou melhor, a "materialidade" do material investigado.

A quarta etapa de leitura, denominada "amplificação", permitiu-nos estabelecer analogias e paralelos entre os sentidos obtidos na amostra, formada por textos de Jung e de seus comentados ligados à Psicologia Analítica, e os textos da Física Quântica. Dessas analogias e paralelos, criamos uma interlocução entre esses dois campos do conhecimento para elucidar novos significados contidos na visão de mundo engendrada pelo conceito de unus mundus.

Tal aproximação nos pareceu legítima, uma vez que Jung se aproximou dessa disciplina, em muitos momentos de sua obra, para esclarecer seus pontos de vista (Jung, Pauli, Meier, Roscoe, \& Zabriskie, 2014). Samuels (1989, p. 149) também legitimou nossa escolha de amplificação ao afirmar que a noção de unus mundus traz desafios ao campo junguiano, pois "Por ser o assunto da psicologia tão difícil de apreender, os analistas junguianos, constantemente, fazem [. . .] incursóes em outros campos, em busca de ajuda para melhor definir seu material". A amplificação, assim como o produto da leitura produzido com os procedimentos mencionados acima, foi apresentada na seção de resultados deste trabalho.

Após a última etapa de leitura, os sentidos recorrentes do material lido deram origem às quatro categorias de análise por meio das quais os resultados a seguir foram organizados: "o plano invisível subjacente ao nível empírico da realidade como totalidade e unidade", "o plano invisível como fonte de criação e de movimento", "o plano invisível como marcado pela não localidade" e "a psique e o plano invisível”. 


\section{RESULTADOS}

Para cada uma das categorias, a seguir, apresentamos comentários analíticos com vistas a esclarecer aspectos da visão de mundo e os sustentamos por meio de citações diretas ou indiretas dos textos da amostra.

\subsection{O plano invisível subjacente ao nível empírico da realidade como totalidade e unidade}

Jung (1991) criticou a crença científica de que o plano empírico corresponde à totalidade do que se conceitua como "realidade" ao colocar em questão "o célebre princípio: Nibil est in intellectu quod non antea fuerit in sensu [nada existe no intelecto que antes não tenha passado pelos sentidos]" (p. 331, \$742). Esse autor afirmou que, de forma equivocada, a ciência considera

"Real" tudo o que provém ou pelo menos parece provir direta ou indiretamente do mundo revelado pelos sentidos [. . . ]. A limitação do conhecimento à realidade material arranca um pedaço excessivamente grande, ainda que fragmentário, da realidade total (Jung, 1991e, p. $332, \$ 743)$.

Para ultrapassar esse equívoco, ele propôs que "Nosso conceito prático de realidade [. . .] precisa de revisão, e tanto é assim, que a literatura comum e diária começa a incluir os conceitos de 'super' e 'supra' em seu horizonte mental. Estou de pleno acordo com isto" (Jung, 1991e, p. 332, \$745). Essa proposição de Jung, segundo ele mesmo, explicou, foi influenciada por autores anteriores à época cristã, por exemplo, Teofrasto, para quem o suprassensível e o sensível estão unidos por um vínculo de comunhão e, de forma similar, Plotino, quando afirmou que as almas individuais são originadas da Alma do Mundo. A concepção platônica de realidade também se comunica com essas proposições de Jung (Nagy, 2003).

Apesar da importância de todas as referências acima mencionadas, para a proposição de um plano invisível da realidade, a Alquimia medieval que se configurou como um campo de saber e de práticas da Europa na referida época, parece ser a mais relevante na obra de Jung. O estudo sobre a Alquimia direcionou-o à ideia de unus mundus ou de um mundo unitário que serviu de base para sua formulação de realidade suprassensível e, assim, constituir aspectos importantes da visão de mundo da Psicologia Analítica (Samuels, 1993). Baseado nessa concepção, Jung (1990) propagou a perspectiva de que a realidade sensível está embasada em um "mundo potencial [. . . ] a razão última e eterna de todo o ser empírico” (p. 291, \$414). 
Para Jung (1990), o unus mundus é a unidade latente do mundo sobre a qual a multiplicidade do empírico repousa, correspondendo ao "mundo transcendental" ou "suprassensível" por estarem contidas nele todas as condiçôes que determinam a forma dos fenômenos empíricos. O adjetivo "transcendental", utilizado para qualificar o unus mundus, tem sentido equivalente a potencial e extratemporal. Esse pensador suíço acrescentou que "transcendente" é aquilo que é incógnito ou além do conhecimento direto, pois pode ser abordado apenas indiretamente por meio de suas manifestações e irradiações (Jung, 2003).

Com a noção alquímica de unus mundus, Jung compartilhou da intuição schopenhaueriana de que a base da realidade é uma unidade e, assim, definiu mais uma propriedade para sua formulação de plano suprassensível como aspecto da realidade. $\mathrm{O}$ unus mundus dos filósofos medievais, os quais foram praticantes da Alquimia, transcende a divisão cartesiana de mente e corpo, assim como as nossas categorias humanas de espaço, de tempo e de causalidade (Stevens, 2015).

O unus mundus "Manifesta-se [. . .] não apenas nos seres humanos, mas também ao mesmo tempo em animais e inclusive em circunstâncias físicas" (Jung, 2002a, p. 399). Jung (2002a) propôs o unus mundus como dotado de todas as pré-condiçôes que determinam a forma do fenômeno empírico, tanto psíquico como físico. Samuels (1993) sugere que esse conceito é usado por Jung para propor que cada extrato da existência está intimamente ligado com todos os outros, além de indicar a existência de um supraordenado e transcendente plano que coordena as partes separadas.

Na Psicologia Analítica, o significado de unus mundus foi, por vezes, também expresso pelo de anima mundi, da terminologia alquímica, a qual restringe esse termo como uma força natural que seria responsável por todos os fenômenos da vida e da psique (Jung, 1991c). A qualidade essencial da alma é a de vivificar e de ser viva, por isso é corretamente representada como princípio de vida. Com o seu conceito de anima mundi, os alquimistas referem-se à alma do mundo, ao que seria um espírito do mundo macrocósmico e microcósmico do qual dependeriam a mobilidade e a fluidez da natureza humana (Jung, 2003).

Jung (2002b) explicou que a perspectiva contida em unus mundus, de que existe correspondência ou simpatia entre os diferentes elementos da realidade, tem origem em doutrinas filosóficas da Antiguidade, que admitem relação de dependência entre as diferentes partes do cosmos. Essas doutrinas baseiam-se no pressuposto de que há também um princípio universal na menor parte de algo e que, por isso, esta concorda com todas as demais partes e com o todo.

Zinkin (1998) propôs para a Psicologia Analítica o holograma como metáfora para se referir à relação entre as diferentes partes do plano empírico com o plano 
invisível o qual, subjacente ao visível, gera totalidade e unidade à aparente fragmentação do âmbito manifesto. Para Zinkin (1998), o holograma encarna essa visão alquímica, presente na Psicologia Analítica, de que a parte contém o todo e, em alguma medida, o representa e expressa no plano empírico:

As ideias geradas pelo holograma são [. . .] de que tudo é um fluxo, que o mundo não é muitos, mas apenas um, que o microcosmo reflete o macrocosmo e que a totalidade do mundo pode ser vista em um grão de areia. [. . . Essa visão está substituindo o paradigma reducionista causal-mecanicista em vigor nos últimos cem anos nas ciências naturais. [. . .] É o holograma que nos oferece uma base teórica sólida para esse conhecimento. Nós descobrimos [...] que uma parte por menor que seja que parece ser um fragmento pode ser iluminada para revelar a totalidade. Pode-se dizer que tais proposiçōes são indubitavelmente novas; os alquimistas, por exemplo, talvez tenham pensado do mesmo modo sobre o que ocorria em suas experiências (Zinkin, 1998, pp. 117, 128).

A holografia é um método de fotografia a laser, que resulta em um holograma, o qual é uma imagem tridimensional do objeto do qual o holograma foi produzido. Um holograma presentifica a aparência do objeto original, ainda que este não esteja mais presente. No holograma, as partes contêm o todo, o qual é composto por elas, sendo que cada uma reflete o todo, ao menos na extensão de que cada parte expressa, e manifesta algumas qualidades dele (Burke, 2003). Uma parte, por menor que seja, pode ser iluminada para revelar a totalidade (Zinkin, 1998).

Posto isso, afirmamos que Jung (1969), em sua visão de mundo ancorada no conceito de unus mundus, propôs a realidade

Como num corpo vivo, as diferentes partes trabalham em harmonia e estão significativamente ajustadas umas com as outras, assim também os acontecimentos do mundo se acham mutuamente numa relação significativa, que não pode ser deduzida da causalidade imanente (p. 491, 5927$)$.

\subsection{O plano invisível como fonte de criação e de movimento}

O plano invisível também foi definido por meio da palavra gnóstica pleroma na obra de Jung e mantém relações aproximadas com o conceito de unus mundus. Essa palavra pertenceu ao vocabulário dos gnósticos: cristãos que, a partir dos séculos II e III d.C., resistiram às exigências impostas pelas autoridades dessa religião bem como a aceitar suas proposições. Esses cristãos "rebeldes" procuravam por um conhecimento diferente daquele dogmático, o qual foi definido pela palavra grega gnose. Para os gnósticos, pleroma é o termo que representa a plenitude do divino ou do mundo invisível. Este representa o Reino do Deus desconhecido. 
Se o pleroma é caracterizado pelo estado de unidade sem forma, ele é fonte de criação que se torna dual ao ingressar no mundo sensível, havendo, assim, a separação entre o mundo visível e o invisível (Singer, 2002).

Hoeller (1991) afirma que Jung empregou a palavra em questão e propôs que os opostos são qualidades do pleroma, mas nele estão inexistentes porque se anulam mutuamente. Os opostos são apenas visíveis no âmbito empírico, já que, no plano invisível, existem apenas como dualidade potencial. O pleroma carrega em si a criação e o estado de unidade que tendem a aparecer sob a forma dual, visível, distinta, concreta ou definida, no âmbito aparente.

Samuels (1993) esclarece que o termo gnóstico pleroma mantém forte associação com a Física Quântica, por meio do conceito de ordem implicada proposto por Bohm. Esta palavra gnóstica foi usada por Jung "para designar um 'lugar' além das categorias de tempo-espaço [. . .] em que as tensões entre os opostos são extintas. [. . .] correspondendo ao que [. . .] Bohm definiu como ordem implicada da realidade que é subjacente à percebida" (Samuels, 1993, p. 109). Bohm e Jung exploraram uma visão do universo como totalidade, uma engrenagem da qual todos nós somos parte e de onde ninguém pode se separar. Eles partiram do pressuposto de que existe uma realidade subjacente às diferentes partes da realidade empírica (Carr, 2003).

O conceito de ordem implicada (realidade potencial) proposto por Bohm está, por outro lado, também relacionado com o de unus mundus, ou seja, com a existência de um âmbito potencial e de criação da realidade subjacente ao empírico (Bohm, 1990; Carr, 2003; Singer, 2002). Com os conceitos de ordem explicada e implicada, Bohm (1990) cria uma convergência importante com a visão de realidade articulada por Jung:

Eu desenvolvi a noção de ordem explicada [realidade manifesta] e de ordem implicada. A característica essencial foi de que todo o universo está de algum modo presente em tudo e que cada coisa está associada ao todo. [. . . . A ordem explicada, que domina a experiência ordinária [. . .], portanto aparece como subsistindo por si mesma. Mas, na realidade, ela não pode ser entendida adequadamente sem considerá-la em seu enraizamento na realidade primária da ordem implicada (p. 273).

Nesses termos, é possível afirmar que Jung (1990) reconheceu, na Física Quântica, uma possibilidade de relação com a Psicologia Analítica para manter a concepção de um mundo invisível sob o qual o empírico estaria sustentado e interconectado. A matéria, objeto de estudo da microfísica, e a psique, da Psicologia, parecem ter um fundamento comum na realidade, ou seja, estão enraizadas em um âmbito suprassensível e transcendental do que se reconhece como real, conforme afirma o extrato a seguir: 
O fundo comum da microfísica e da chamada psicologia do profundo é tanto físico como psíquico, e por isso não é nenhum dos dois, mas antes uma terceira coisa, uma natureza neutra, que no máximo pode ser concebida por meio de alusões, pois a natureza profunda dela é transcendental (Jung, 1990, p. 295, \$423).

Pautada pela Psicologia Analítica, em diálogo com autores da Física Quântica, como Bohm, a junguiana Pereira (1998) enfatizou, com base na noção de unus mundus, o movimento como propriedade do plano suprassensível articulado por Jung. Sob essa perspectiva, a realidade não manifesta, que é potencial de tudo o que se manifestará no mundo concreto, tem como característica essencial a de ser um fluxo, ou seja, a de ser um movimento contínuo.

Qualquer evento, objeto ou entidade descritível é considerado como um aspecto ou uma faceta da totalidade desconhecida e indefinível de movimento fluente, pois a natureza é fluxo. Na realidade profunda, o movimento é a realidade primária. $\mathrm{O}$ mundo não manifesto é energia potencial daquilo que se manifesta no mundo visível. Nesse sentido, apreender a realidade como unidade pressupóe a ideia de fluxo de energia e de um movimento contínuo de mudança que lhe é inerente. O movimento contínuo que se define pelo conceito de energia é a base criativa da realidade manifesta, pois ele encerra sempre novas possibilidades de concretizaçôes (Pereira, 1998).

\subsection{O plano invisível como marcado pela não localidade}

No plano suprassensível para Jung ou na ordem implicada para Bohm, o tempo e o espaço não são absolutos, pois aquele é dotado da propriedade não local. $\mathrm{O}$ plano invisível traz uma importante consequência para a realidade empírica: confere-lhe a propriedade da não localidade. Como propôs Herbert (1988), os experimentos de Bell no campo da Física Quântica permitiram sustentar a hipótese da não localidade presente na noção de unus mundus da obra junguiana.

Ao retomar os experimentos de Bell, Herbert (1988) esclareceu o princípio da "não localidade" como distinto da usual perspectiva de causa e efeito do princípio da "localidade". A ciência ortodoxa mantém a visão de realidade marcada pelo princípio da "localidade", que se assenta na lógica da causa e efeito. Toda relação de causa e efeito é mediada por alguma interação local, ou seja, pelo princípio da localidade. Segundo esse princípio, por exemplo, a engrenagem de uma máquina se movimenta ao encontrar com outro dispositivo que a ativa mecanicamente.

Por outro lado, diferentemente da perspectiva da "localidade", há relações "não locais" marcando a conexão entre as diferentes partes da realidade e a produção das ocorrências. Desse modo, por exemplo, quando A se conecta a B não 
localmente, nada intervém no espaço comum; portanto nenhuma quantidade de matéria interposta pode impedir ou promover essa interação. As influências não locais podem ser definidas como aquelas as quais não diminuem com a distância e atuam instantaneamente. Além disso, essas conexões não mediadas estão presentes e subjazem a todos os eventos da vida cotidiana. As conexões não locais são ubíquas porque a realidade, em sua essência, é não local (Herbert, 1988).

Embora seja difícil delinear características precisas para esses dois mundos, o visível e o invisível, é possível atribuir-lhes modos de funcionamento distintos. O mundo empírico tem como características a ordem e estabilidade, a matéria, a forma, as partes (os itens), o objetivo, a definição, a conclusão, o contingenciamento do tempo e do espaço. O invisível, por sua vez, tem como propriedades o caos e o fluxo, a energia, o formativo, o sistema, o processo, o indefinido, o infinito, a condição de permanente evolução e a não localidade (Singer, 2002).

\subsection{A psique e o plano invisível}

Jung (1991a) defende essa perspectiva unitária da realidade, da qual a psique faz parte, ao propor que a psique "participa, em suas camadas mais profundas, de uma forma de existência transespacial e transtemporal e que, por consequência, pertence àquilo que [. . . e é designado pelo nome de 'eternidade' [o unus mundus]" (p. 367, \$ 815). O consciente e o inconsciente "são vivências psíquicas que se apoiam num fundamento obscuro e indevassável” (Jung, 2001, p. 94, $\$ 355$ ). O homem, assim como os demais componentes da realidade empírica, estão ligados ao fundamento do mundo, plano invisível da realidade. Jung (1990) propôs que o "próprio homem em parte é empírico, em parte é transcendental" (p. 294, \$421).

Nesses termos, a psiqueé parte que se comunica ese alimenta fundamentalmente dessa base unificadora da totalidade da realidade, ou seja, o unus mundus. A consciência é conceituada como campo de manifestação de uma realidade mais abrangente, existente a priori que se expressa e forma o campo visível do consciente (Pereira, 1991). O todo está contido ou refletido em cada parte que o compõe, incluindo-se, assim, também a psique nessa filiação com o todo (Burke, 2003).

Para Jung (1982) a "ponte" entre o psíquico e o unus mundus é estabelecida mediante o conceito de arquétipo que "representa uma condição ou base da psique em geral, universalmente presente e sempre idêntica a si mesma” (p. 5, \$12). O 
arquétipo pertence ao inconsciente que Jung denominou como coletivo já que constituído e herdado pela história da espécie e não do indivíduo (Jung, 1982).

Ao conceituar arquétipo, Jung (2014) diferenciou "arquétipo como forma", geradora de tendências de representação e de apreensão da realidade na psique, de "arquétipo como tal" também denominado pelos termos "arquétipo em si" ou "psicoide":

As representações arquetípicas (imagens e ideais) mediadas por nós pelo inconsciente não devem ser confundidas com o arquétipo como tal [. . .] "irrepresentável”. [. . .] O arquétipo em si é um fator psicoide que pertence, por assim dizer, ao invisível, extremo ultravioleta do espectro psíquico. Não parece, por si só, ser capaz de alcançar a consciência ( $\$ 417)$.

Nesses termos, Jung (2014) ainda explicou que

Violeta é a cor "mística", e certamente reflete a qualidade indiscutível "mística" ou paradoxal do arquétipo da maneira mais satisfatória. [. . .] Parece-me provável que a verdadeira natureza do arquétipo não seja capaz de tornar-se consciente, pois é transcendente, e o chamo de psicoide $(\$ \$ 414,417)$.

Os "arquétipos são os componentes mediadores do unus mundus" (Card, 1991, p. 29), e exercem essa função quando considerados em seu âmbito "psicoide", como atesta o fragmento seguinte de Jung (1958/1964):

A natureza psicoide do arquétipo contém muito mais do que pode ser incluído em uma explicação psicológica. Aponta para a esfera do unus mundus, o mundo unitário, em direção ao qual o psicólogo e o físico atômico estão convergindo em caminhos separados, produzindo independentemente uns dos outros certos conceitos auxiliares análogos. Embora o primeiro passo no processo cognitivo seja discriminar e dividir, na segunda etapa ele unirá o que foi dividido, e uma explicação será apenas satisfatória quando atingir uma síntese (\$ 852).

Como esclarecido acima, o arquétipo e o plano invisível, unus mundus, não são diretamente accessíveis já que pertencem ao plano que Jung denominou como transcendental. A evidência do funcionamento conjunto de ambos é criada à consciência e ao plano visível das formas empíricas mediante os fenômenos que Jung denominou de sincronicidade. A sincronicidade evidencia o encontro entre o interno, psicoide, e o unus mundus, de diferentes maneiras.

Segundo Samuels (1993), a sincronicidade refere-se a eventos nos quais a correspondência de sentido entre os aspectos psíquicos e as ocorrências visíveis no mundo material não pode ser explicada por meio de relação causal, de tempo e de espaço. Trata-se da relação entre dois fenômenos que pertencem a âmbitos 
diferentes, compreendida por um princípio não causal (Samuels, 1993). Nesses termos, "A sincronicidade ocorre onde dois diferentes âmbitos da realidade (por exemplo, mundo interno e externo) se interceptam" (Samuels, 1993, p. 147), já que "o arquétipo [. . .], com sua natureza psicoide, forma a ponte para a matéria em geral” (Jung, 2014, \$420).

Jung (1969) evidenciou a tese acerca da sincronicidade em vários momentos de sua obra, contudo, talvez, um dos mais inspiradores seja o de um relato de uma sessão na qual ele trabalhou o sonho de uma paciente sobre um besouro. Jung esclareceu que, quando ela lhe contava que havia ganhado uma joia cara, um escaravelho dourado (besouro), ele ouviu algo batendo na janela do lado de fora. Quando ele abriu a janela, encontrou um besouro escaravelho que pegou em sua mão e, ao notar, sua cor verde-dourado parecida com a do escaravelho dourado no sonho da sua cliente, ele entregou o besouro à paciente e disse: "Aqui está o seu escaravelho".

\section{REFLEXÃO E CONSIDERAÇÕES FINAIS}

Este artigo partiu do pressuposto de que esclarecer aspectos da visão de mundo contida na Psicologia Analítica traria contribuiçôes para o entendimento desse recorte científico em Psicologia, uma vez que lançaria luz sobre a imagem de realidade que (re)cria ao ser empregado nos diferentes contextos de sua aplicação como a pesquisa e a clínica.

Nesses termos, este estudo permitiu identificar que o conceito de unus mundus da Alquimia Medieval, assim como seu correlato anima mundi, também do mesmo campo de conhecimento, e a noção gnóstica de pleroma são centrais na obra de Jung quando ele revisita e desafia o conceito de realidade como sinônimo de mundo sensível, empírico, visível. Com o papel central do conceito de unus mundus, Jung articula uma visão de mundo na Psicologia Analítica, na qual a realidade empírica, visível, marcada pelos princípios de explicação causal e categorias do tempo e do espaço, corresponde apenas a um aspecto do que Jung conceitua como realidade.

A amostra deste estudo, investigada mediante a hermenêutica junguiana, permitiu identificar que o plano empírico da realidade é visto como enraizado em um plano invisível, transcendental, que pode ser definido como totalidade indivisa e de movimento que encerra fluxo infinito de potencialidades para novas configurações do plano visível. Cada parte do âmbito visível em razão da filiação com o unus mundus expressa, de modo particular, a totalidade. O "todo" está contido, assim, na "parte”, que o expressa parcialmente no plano empírico 
e carrega seu potencial porque se mantém conectada a ele. Essas conclusões, quando amplificadas com o conceito de ordem implicada de Bohm, ganham ressonância e evidenciam formulações semelhantes nestes dois campos do conhecimento: Psicologia e Física.

O âmbito invisível cria ligação não local entre as partes e revela a unidade subjacente, não condicionada pelo tempo e espaço, por meio dos eventos "a-causais" aos quais Jung denomina "sincronicidade". O arquétipo considerado em sua natureza "psicoide" inscreve, na teoria da Psicologia Analítica, o transcendental na psique, ao ser tomado como função "ponte" de conexão com o invisível. Os eventos de sincronicidade que ligam a realidade material e os eventos psíquicos, como sonhos e fantasias, são considerados por Jung como evidência da conexão entre a psique com o unus mundus e, portanto, do plano invisível da realidade.

A evidência, entretanto, de ordem "a-causal" encontra sua materialidade e força no campo do sentido, pois é o significado que liga as ocorrências que pertencem a âmbitos diferentes, como o sonho comum de um besouro e o animal besouro na realidade empírica da paciente de Jung.

Posto isso, Jung parece desafiar ainda hoje a visão de mundo prevalecente nas diferentes teorias em Psicologia, pois parte da realidade empírica e especula sobre o transcendental para conseguir compreender fenômenos que tratou em sua teoria, como a sincronicidade, propondo uma visão de mundo marcada pela unidade.

Antes de encerrarmos, é preciso esclarecer que este estudo apresenta limites na consecução de seu objetivo, em razão do recorte escolhido. Em primeiro lugar, a amostra deste estudo privilegiou o conceito de unus mundus e noções associadas a ele para responder ao objetivo deste artigo. Em segundo lugar, a amostra deste estudo se restringiu a textos da vertente clássica dessa disciplina em detrimento de tantas hoje existentes.

Concluímos, assim, que o recorte deste artigo, apesar de parcial, tornou possível lançar luz sobre diversos aspectos da visão de mundo da Psicologia Analítica em sua vertente clássica que, como um símbolo vivo, encontra-se ainda aberta para novas e inéditas apreensões de sentido em futuros trabalhos. 


\section{REFERÊNCIAS}

Bohm, D. (1990). A new theory of the relationship of mind and matter. Philosophical Psychology, 3(2), 271-286.

Boyd, R. D. (1991). Personal transformations in small groups: a Jungian perspective. New York: Routledge.

Burke, J. W. S. (2003). Strange attractors: transference, holography, and an archetype. (Doctoral Dissertation). Pacifica Graduate Institute, Santa Barbara.

Card, C. R. (1991). The archetypal view of C. G. Jung and Wolfgang Pauli Part I. Psychological Perspectives, 24, 19-33.

Carr, J. (2003). The lives and theories of two creative giants: Carl Jung and David Bohm. (Master's Thesis). Saybrook Research Institute and Graduate School, San Francisco.

Cochrane, M., Flower, S., Mackenna, C., \& Morgan, H. (2014). A Jungian approach to analytic work in the tweinty-first century. British Journal of Psychotherapy, 30(1), 33-50.

Forryan, B., \& Glover, J. M. (1979). General index to the collected works of C. G. Jung (Bollingen Series XX). Princeton: Princeton University Press.

Hard, D. L. (2008). The classical Jungian School. In P. Young-Eisendrath, \& T. Dawson, The Cambridge Companion to Jung ( $2^{\text {nd }}$ ed., pp. 95-106). Cambridge: Cambridge University Press.

Herbert, N. (1988). How Bell proved reality cannot be local. Psychological Perspectives, 19(2), 313-319.

Hoeller, S. A. (1991). A gnose de Jung e os sete sermões aos mortos (2a ed.). São Paulo: Cultrix.

Humbert, E. G. (1985). A atividade do consciente: três verbos. In E. G. Humbert, Jung. (pp. 19-23). São Paulo: Summus.

Jung, C. G. (1991d). Psicologia Analítica e cosmovisão. In C. G. Jung, Obras completas de C. G. Jung (3a ed., Vol. 8/2: A natureza da psique, pp. 303-328). Petrópolis: Vozes, 1991. (Publicado originalmente em 1928-1931).

Jung, C. G. (2001). Obras Completas de C. G. Jung (Vol. 7/2: O eu e o inconsciente). Petrópolis: Vozes, 2001. (Publicado originalmente em 1928). 
Jung, C. G. (1991e). O real e o suprarreal. In C. G. Jung, Obras completas de C. G. Jung (3a ed., Vol. 8/2: A natureza da psique, pp. 331-333). Petrópolis: Vozes, 1991. (Publicado originalmente em 1933).

Jung, C. G. (1991a). A alma e a morte. In C. G. Jung, Obras Completas de C. G. Jung ( $3^{a}$ ed., Vol. 8/2: A natureza da psique, pp. 355-367). Petrópolis: Vozes, 1991. (Publicado originalmente em 1934).

Jung, C. G. (1977). Tavistock lectures: 1. In The Collected Works of C. G. Jung Bollingen Series XX. (Vol. 18: The symbolic life: miscellaneous writings, pp. 5-35). Princeton: Princeton University Press, 1977. (Original work published in 1935).

Jung, C. G. (2003). O espírito mercurius. In C. G. Jung, Obras Completas de C. G. Jung (Vol. 13: Estudos alquímicos, pp. 189-243). Petrópolis: Vozes, 2003. (Publicado originalmente em 1943-1948).

Jung, C. G. (1991b). Psicoterapia e atualidade. In In C. G. Jung, Obras Completas de C. G. Jung (Vol. 16/1: A prática da psicoterapia, pp. 90-105). Petrópolis: Vozes, 1991. (Publicado originalmente em 1945).

Jung, C. G. (1991c). Considerações teóricas sobre a natureza do psíquico. In C. G. Jung, Obras completas de C. G. Jung ( $3^{\mathrm{a}}$ ed., Vol. 8/2: A natureza da psique, pp. 99-171). Petrópolis: Vozes, 1991. (Publicado originalmente em 1946).

Jung, C. G. (1982). Obras completas de C. G. Jung (Vol. 9/2: Aion: estudos sobre o simbolismo do si-mesmo, 2a ed.). Petrópolis: Vozes, 1982. (Publicado originalmente em 1951).

Jung, C. G. (1952/1969). Synchronicity: an acausal connecting principle. In C. G. Jung, The collected works of C. G. Jung ( $2^{\text {nd }}$ ed., Vol. 8: The structure and dynamics of the psyche, pp. 418-519). London: Routledge\& Kegan Paul, 1969. (Original work published in 1952).

Jung, C. G. (1954/2014). On the nature of the psyche. In The complete digital edition of the collected works of C. G. Jung (Vol. 8: Structure and dynamics of the psyche). Princeton: Princeton University Press, 2014. (Original work published in 1954).

Jung, C. G. (1955-1956/1990). Obras completas de C. G. Jung. (Vol. 14/2: Mysterium coniunctionis, pp. 210-312). Petrópolis: Vozes, 1990. (Publicado originalmente em 1955-1956). 
Jung, C. G. (1958/1964). A psychological view of conscience. In C. G. Jung, The complete digital edition of the collected works of C. G. Jung (Vol. 10: Civilization in transition). Princeton: Princeton University Press, 1964. (Original work published in 1958).

Jung, C. G. (1972/2002a). Cartas 1906-1945. (2ª ed.). Petrópolis: Vozes, 2002 (Publicado originalmente em 1972).

Jung, C. G. (1972/2002b). Cartas 1946-1955. Petrópolis: Vozes, 2002. (Publicado originalmente em 1972).

Jung, C. G. (2003). Cartas 1956-1961. Petrópolis: Vozes, 2003.

Jung, C. G., Pauli, W., Meier, C. A., Roscoe, D., \& Zabriskie, B. (2014). Atom and archetype: The Pauli/Jung letters, 1932-1958. Princeton: Princeton University Press.

Nagy, M. (2003). Questôes filosóficas na Psicologia de C. G. Jung. Petrópolis: Vozes.

Pereira, M. R. G. (1991). Um espaço para a individuação: o masculino e o feminino como pontes à unidade. (Tese de Doutorado). Instituto de Psicologia, Universidade de São Paulo, São Paulo.

Pereira, M. R. G. (1998). Uma proposta de metodologia em Psicologia Analítica: material didático do curso de pós-graduação em Psicologia Analítica. São Paulo: Cogeae PUC-SP.

Samuels, A. (1989). Jung e os pós-junguianos. Rio de Janeiro: Imago.

Samuels, A. (1993). A critical dictionary of Jungian analysis. London: Routledge.

Samuels, A. (2017). The future of Jungian analysis: strengths, weaknesses, opportunities, threats ('SWOT'). London: The Society of Analytical Psychology, University of Essex. Recuperado a partir de http://www.andrewsamuels.com/ wp-content/uploads/SAP-LECTURE-SAMUELS-2017-final.pdf

Singer, J. (2002). A mulher moderna em busca da alma: guia junguiano do mundo visivel e do mundo invisivel. São Paulo: Paulus.

Stevens, A. (2015). Archetype revisited: an update natural history of the Self. New York: Routledge.

Vechi, L. G. (2021). A psicologia junguiana aplicada em instituiçôes (3a ed., rev. e ampl.). Curitiba: Appris. (no prelo) 
Vechi, L. G. (2018). A hermenêutica junguiana em estudo: aplicações possíveis na pesquisa qualitativa em Psicologia. Revista de Psicologia da Universidade Federal do Ceará, 9(2), 21-30. Recuperado a partir de http://www.periodicos. ufc.br/psicologiaufc/article/view/18806

Von Franz, M. L. V. (1974). Number and time. Evanston: Northwestern University Press.

Von Franz, M. L.V. (2001). Psyche and matter. Boston: Shambala.

Zinkin, L. (1998). The hologram as a model for analytical psychology. In Zinkin, H., Gordon, R., \& Haynes, J. (Eds.), Dialogue in the analytic setting: selected papers of Louis Zinkin on Jung and on group analysis. (pp. 116-134). London: Jessica Kingsley. 